\title{
La organización productiva y del trabajo en los noticieros de cuatro ciudades argentinas
}

\author{
Ekoizpenaren eta lanaren antolakuntza Argentinako lau hiritako albistegietan \\ The productive and labour organization in news outlets \\ of four Argentine cities
}

\author{
Ornela Vanina Carboni $\star$ \\ Universidad Nacional de Quilmes
}

\begin{abstract}
RESUMEN: El trabajo analiza la estructura productiva de los noticieros emitidos en el horario central nocturno en las ciudades de Buenos Aires, Rosario, Mendoza y Córdoba, específicamente en los temas de violencia, delito e inseguridad. En términos metodológicos se realizaron 45 entrevistas en profundidad a actores clave que integran los equipos de trabajo de los noticieros estudiados y se efectuaron observaciones in situ en las emisoras. Las experiencias permitieron comprender las rutinas de trabajo, especialmente en la selección, recolección, tratamiento y puesta al aire de los noticieros, y revelaron las diferencias y similitudes de cada polo productivo.
\end{abstract}

PALABRAS CLAVE: estructura productiva; rutinas de trabajo; noticieros; televisión.

ABSTRACT: The work analyzes the productive structure of newscasts during prime time in the cities of Buenos Aires, Rosario, Mendoza and Córdoba, specifically on the topics of violence and crime. In methodological terms, 45 in-depth interviews were conducted with key actors who are part of the news teams studied and on-site observations were made at the stations themselves. The experience allowed us to understand the work routines, especially in the selection, collection, treatment and airing of the newscasts, and revealed the differences and similarities of each productive pole.

KEYWORDS: productive structure; work routine; news; television.

\footnotetext{
* Correspondencia a / Corresponding author: Ornela Vanina Carboni. Universidad Nacional de Quilmes (UNO) es Roque Saénz Peña 352. Bernal, Pcia. de Buenos Aires, Argentina - ornelacarboni@yahoo.com.ar - https://orcid.org/0000-0002-3968-6455

Cómo citar / How to cite: Carboni, Ornela Vanina (2020). «La organización productiva y del trabajo en los noticieros de cuatro ciudades argentinas"), Zer, 25(48), 165-189. (https://doi.org/10.1387//zer.21414).

Recibido: 26 enero, 2020; aceptado: 21 marzo, 2020.

ISSN 1137-1102 - eISSN 1989-631X / (c) 2020 UPV/EHU

(c) (i) Esta obra está bajo una licencia

Creative Commons Atribución 4.0 Internacional
} 


\section{Introducción. Estructura productiva y rutinas de trabajo en los noticieros prime time}

Los procesos de organización productiva y del trabajo han sido escasamente investigados al interior de las industrias culturales, no obstante diversos investigadores advirtieron sobre la importancia de explorar este campo puesto que afecta la realización del contenido final, su distribución y consumo.

El académico canadiense Vincent Mosco $(2009,2011)$ alertó sobre la necesidad de examinar la mercantilización del trabajo dentro del proceso de producción de contenidos en el conjunto de las industrias culturales. El autor sostiene que desde el campo de la comunicación se investigaron los contenidos de los medios y las audiencias, pero se relativizó el rol de los trabajadores culturales.

David Hesmondhalgh y Sara Baker (2010) resaltan los exiguos estudios sobre los trabajadores dentro de las industrias culturales. Los autores se focalizan en el trabajo creativo y mencionan los abordajes realizados desde la sociología del trabajo, los estudios de management, los negocios y las organizaciones que han incluido a los trabajadores, aunque no han hecho hincapié en las industrias culturales.

Por su parte, Tremblay (2011) y Mosco (2009) coinciden en que las condiciones laborales impuestas a los trabajadores en diversas áreas de producción industrial se asemejan con frecuencia a las características de los sectores de la cultura y la comunicación. Esas condiciones se asocian a la creatividad, la calidad del producto, la flexibilidad, la versatilidad, la imaginación, la novedad y la precariedad de los empleos.

En síntesis, este trabajo parte de un marco conceptual que incluye nociones de la Economía Política de la Comunicación para comprender los rasgos de la industria televisiva y la lógica de emisión de flujo, de la Sociología del Trabajo para retomar las categorías de análisis ligadas a las economías de tiempo, la división del trabajo, los mecanismos de coordinación y control, el código de trabajo - control interno- y el código laboral — control externo- (Roldán, 2010; 2011), y de la perspectiva del Newsmaking que articula la cultura profesional de los periodistas, la organización del trabajo y los procesos productivos (Wolf, 1987), con la propuesta de echar luz sobre los procesos de trabajo y las condiciones laborales en la producción de los noticieros televisivos.

Por lo expuesto, el objetivo es analizar la estructura productiva de los noticieros emitidos en horario central nocturno en las ciudades de Buenos Aires ${ }^{1}$, Rosario,

\footnotetext{
1 A partir de ahora al referirnos a la ciudad de Buenos Aires, diremos AMBA (Área Metropolitana de Buenos Aires) por el lugar físico y geográfico en el cual se ubican las emisoras estudiadas.
} 
Mendoza y Córdoba específicamente en los temas de violencia, delito e inseguridad. Esto se debe a que la investigación es parte del Proyecto de Investigación Orientado (PIO) y del Proyecto de Investigación en Ciencia y Tecnología (PICT), denominados «De la propiedad a la recepción. Estudio integral del circuito productivo de las noticias sobre delito e inseguridad en los noticieros televisivos de mayor audiencia de la Argentina», los cuales abordan de modo integral la producción de noticias ${ }^{2}$. Kessler y Focas (2014) aseguran que en los últimos veinte años aumentó la preocupación de la ciudadanía sobre el crecimiento del delito, de modo consecuente los medios de comunicación incrementaron la difusión de este tipo de hechos, y esto habría conllevado a un aumento del sentimiento de inseguridad. Kessler (2009) lo define como la sensación de una amenaza aleatoria que puede abatirse sobre cualquiera en cualquier lugar. La inseguridad posee dos dimensiones: la objetiva (tasa de delitos elaboradas de acuerdo a las denuncias efectivas y encuestas de victimización) y la subjetiva (grado de temor y otros sentimientos expresados por los individuos). Asimismo, en el caso de la televisión su efecto se potencia cuando los individuos identifican una experiencia similar y se hallan cercanos geográficamente, esto activa el sentimiento de riesgo, indefensión y vulnerabilidad. También, intervienen otras variables en el consumo de noticias: las condiciones sociodemográficas, la tasa real de delito, la condición de género y edad (Kessler \& Focas, 2014) ${ }^{3}$.

Dicho esto, el trabajo se organiza en función del análisis de la estructura productiva, de la selección y elaboración de los temas, y la geolocalización. Además, se describe de modo sucinto la puesta al aire y las economías de tiempo de los informativos.

De modo específico, el estudio aborda las condiciones de producción y los procesos de organización productiva y del trabajo de los noticieros de los canales $11 \mathrm{y}$ 13 del Área Metropolitana de Buenos Aires (AMBA), 10 y 12 de Córdoba, 3 y 5 de

\footnotetext{
2 El estudio aborda el proceso productivo de los noticieros emitidos en el horario central en cuatro ciudades argentinas. Se analizan las emisoras 11 y 13 de AMBA, 3 y 5 de Rosario, 9 y 12 de Córdoba y 7 y 9 de Mendoza. El trabajo compone las diversas fases productivas y de recepción de las noticias sobre delito, violencia e inseguridad en los canales de TV abierta de las citadas ciudades, desde perspectivas complementarias, tales como la economía política de la comunicación y la cultura, la sociología de las redacciones, el Framing, la sociosemiótica de las mediatizaciones, el análisis narrativo y los estudios de recepción.

3 Este comportamiento tuvo su correlato en el aumento de la representación mediática del delito entendido en sentido amplio. Los informes Defensoría del Público de Servicios de Comunicación Audiovisual sobre el monitoreo de programas noticiosos de canales de aire de la Ciudad de Buenos Aires muestran que en 2016, de 17197 noticias monitoreadas el 23\% (4024) se relacionan con «Policiales e 'inseguridad", en tanto que en 2017 el número de noticias monitoreadas ascendió a 19160, de las cuales 28,5\% (5.469) se ligaron a este tópico. En relación al eje «Política», en 2016 el número alcanzó el 7,1\% (1220) y en $20176,8 \%$ (1302).
} 
Rosario y 9 y 7 de Mendoza. La elección de estos noticieros se basa en considerar a los informativos de mayor audiencia en las ciudades más pobladas de la Argentina. A excepción del Canal 10 de Córdoba que es el tercero en audiencia, pero es la única emisora - entre las que integran esta investigación - de carácter estatal, que pertenece a los Servicios de Radio y Televisión de la Universidad Nacional de Córdoba. El objetivo de este trabajo no es analizar la estructura de propiedad de los medios, no obstante la concentración de medios y la centralización productiva en AMBA incide en la producción de contenidos informativos a nivel nacional (ver Anexo, Cuadro I).

En términos metodológicos se procedió a la realización de 45 entrevistas en profundidad a actores clave que integran los noticieros estudiados y a observaciones in situ en las emisoras en los cuales se pudo acceder a los espacios productivos. Las entrevistas se efectuaron entre 2017 y 2018 , de modo personal y casi en su totalidad fuera del ámbito laboral, con el propósito de no condicionar las respuestas. Se les garantizó a los entrevistados el carácter anónimo para preservarlos y fomentar contestaciones genuinas. Por esta razón, no se mencionan sus nombres, se los identifica por el rol laboral que ejercen y la ciudad (ver Anexo, Cuadro II). Cada entrevista se extendió en promedio por una hora y media, y se aplicó una guía previamente confeccionada en función de los objetivos del proyecto. De este modo, el cuestionario se focalizó en el proceso de organización productiva y del trabajo para comprender la elaboración de las noticias, las ramas productivas y los perfiles laborales, esto además permitió comprender las diferencias existentes entre las emisoras de AMBA y el resto de las señales relevadas.

En las preguntas se incluyen aspectos ligados a la selección, elaboración y procesamiento de la información (edición y montaje) específicamente de las noticias de delito, violencia e inseguridad. En la mayoría de las entrevistas fue necesario aclarar qué se entiende por delito, violencia e inseguridad ${ }^{4}$. Además, se consideró la instancia de emisión del noticiero y las economías de tiempo con la intención de observar las etapas de selección y tratamiento de la información con respecto al stock de tiempo para la elaboración de cada pieza informativa. Por último, se indagó sobre la incidencia de la línea editorial del medio en relación a los trabajadores.

Antes de continuar se aclara que se entrevistó a una amplia gama de trabajadores y perfiles laborales para no sesgar los resultados a aquellos que cumplen roles jerárquicos y poder así contrastar las respuestas a partir de las perspectivas de los actores y de la interpretación de sus experiencias.

\footnotetext{
${ }^{4}$ La mayoría de los entrevistados hizo hincapié en el delito a la propiedad privada toda vez que recurrió a ejemplos.
} 


\section{Rutinas y organización del trabajo en los noticieros de la televisión abierta}

\subsection{Conceptos Para El ESTUdio las Rutinas y La ORganización DEL TRABAJO}

La televisión integra al conjunto de las industrias culturales y presenta una serie de rasgos específicos. Uno de los más destacados es la lógica de producción basada en el flujo o emisión continua la cual promueve una organización empresarial que requiere de la definición de una programación diaria. A su vez, la televisión adquirió un rol central en la sociedad e incide en el debate público a través de los diferentes productos que ofrece. Estos productos conllevan altos costos de producción y la conjunción de diversos tipos de trabajo que amalgamados permiten la ejecución del bien (Bustamante, 1999, Tremblay, 2011, Zallo, 1988; 2011, Carboni, 2015).

Desde la sociología del trabajo, Marta Novick (2000) nos brinda una definición completa sobre los procesos de organización productiva y del trabajo:

conjunto de aspectos técnicos y sociales que intervienen en la producción de determinado objeto. Se refiere a la división del trabajo entre las personas, así como entre las personas y las máquinas (...) La organización del trabajo es el resultado del conjunto de reglas y normas que determinan cómo se ejecuta la producción en la empresa. (Novick, 2000, p. 126)

En lo concerniente a los medios de comunicación, los cambios en las formas de organización del trabajo y de valorización se estudian con mayor vigor a partir de 1980 con la irrupción en las empresas informativas de la informática, aunque este proceso se vio ralentizado en América Latina. Entre sus efectos se destaca la aparición de nuevos oficios, la reducción de los costos por la simplificación de las fases de trabajo, la flexibilización y descualificación laboral. Al mismo tiempo, el impacto de las medidas neoliberales provocó un retraimiento de los sindicatos y precarización del trabajo (Azpillaga et al., 1998).

Así pues se pueden entender a las rutinas productivas como una práctica laboral ejecutada de acuerdo a determinadas condiciones materiales y técnicas que se ajustan a una estructura jerárquica y a tiempos de trabajo establecidos (Cesáreo, 1986 en Luzón, 2001). Asimismo, otro valor intangible pero incorporado dentro del proceso productivo es el trabajo creativo que adicionan los trabajadores culturales a los bienes que producen. Este trabajo creativo le imprime un valor único e invaluable al producto final, funciona como una instancia de reconocimiento, de credibilidad y de calidad frente a las audiencias. Además, es imposible soslayar el valor económico que poseen estas producciones, por lo cual el estudio de las rutinas no puede quedar escindido de la reproducción del capital dado que impacta directamente en la elabo- 
ración de las noticias, la toma de decisiones y los recursos técnicos y humanos disponibles.

Por su parte, Gaye Tuchman (1983) se propone estudiar la noticia como construcción social de la realidad. No obstante, el proceso productivo no puede reducirse a fases productivas. "El procesamiento de la noticia se hace rutina de acuerdo con la manera como se piensa que se desarrollan los sucesos en las instituciones legitimadas; predecir el curso que seguirán los relatos de secuencias en instituciones legitimadas permite a los jefes de sección planificar qué reporteros quedarán disponibles, cada día, para cubrir las noticias súbitas» (Tuchman, 1983, p. 226).

En su trabajo Golding y Elliot (1979) describen la producción de noticias a partir de cuatro instancias: planificación (identificar acontecimientos previsibles para asignar recurso y fijar la cobertura diaria a corto plazo), recopilación (los cronistas y periodistas recolectan material para las noticias), selección (se definen el material que se utilizará para el cuerpo de noticias) y producción (los ítem escogidos se acomodan para una presentación ordenada con el objetivo de ser emitidos).

Miquel Alsina (1993) afirma que en la producción se da una interacción entre las fuentes, los medios masivos y el público. La valoración de la noticia se efectúa de acuerdo a tres criterios: la audiencia, la accesibilidad y la conveniencia.

En tanto que, Wolf $(1987)^{5}$ identifica que la escasez de tiempo y los recursos son elementos sustanciales del proceso productivo, y le otorgan relevancia a los valores/noticias. Estos valores/noticia componen uno de los ejes de la noticiabilidad, definida como el conjunto de requisitos exigidos a los acontecimientos para alcanzar estado público. El proceso productivo de un informativo estará compuesto por la recolección, selección y presentación de los hechos, devenidos en noticias.

\subsection{Aproximaciones a las fases productivas de los noticieros EN CUATRO CIUDADES ARGENTINAS}

El noticiero al igual que otros programas audiovisuales puede dividirse en tres fases productivas: la pre producción, la producción per se y la post producción. La

\footnotetext{
5 Mosco (2009) revela una serie de autores que estudiaron la mercantilización del trabajo. Braverman (1974) abordó la transformación del proceso del trabajo en el capitalismo y las tareas de concepción y ejecución del trabajo. Otros autores (Ansberry, 1993; Berberoglu, 1993; Ehrbar, 1993; Zachary y Ortega, 1993) analizan cómo la incorporación de tecnología en los medios de comunicación impactó en la mercantilización del proceso de trabajo. Tuchman (1978), Gans (1979) y Fishman (1980) demuestran que la planificación organizacional y el preprocesamiento sirven para empaquetar y unir las noticias en base a una rutina.
} 
fase de pre producción se inicia unas horas antes de su emisión (entre siete y cuatro de acuerdo a la diagramación de cada emisora). En esta instancia se deciden los principales temas y las coberturas que se realizarán a la tarde o bien el material matutino plausible de ser editado para el noticiero central. La producción per se ocurre al momento de la transmisión en vivo y en directo del informativo. Este tipo de emisión permite cierto grado de flexibilidad con los contenidos que se emitirán y el tiempo que estarán en el aire. En los canales de AMBA existen mediciones de rating minuto a minuto que permiten evaluar el rendimiento de la pieza informativa, en tanto que en el resto de las emisoras estudiadas estas mediciones son de carácter quincenal, por lo cual se guían más por la intuición.

El proceso de post producción difiere de otros contenidos audiovisuales debido a que la compaginación de los hechos o acontecimientos se realiza en tres momentos: previo al noticiero, durante su emisión y posterior al mismo. Esto se debe a que algunas noticias o informes se reeditan para que contenga el desarrollo de ese tema a lo largo del día o de varios días en caso de tratarse de una noticia con continuidad.

En los noticieros de AMBA se realiza regularmente una reunión de producción de la cual participa un reducido grupo: el productor ejecutivo, el editor general, los productores periodísticos, algún periodista y en ocasiones el gerente de noticias. Si bien la mayoría de las emisoras estudiadas cuentan con tres emisiones diarias de informativos, las formas de organización del trabajo difieren. Los canales del AMBA suelen respetar una reunión por cada noticiero, se habla bastante sobre qué y cómo contar, existe pues una mayor rigidez productiva que se deriva, en parte, de la posibilidad de conformar equipos de trabajo más amplios ${ }^{6}$.

En las emisoras del resto del país la situación es diferente. En principio no es posible asegurar la existencia de reuniones de producción sistemáticas como en los canales de cabecera, la escasez de personal conlleva cierta polifuncionalidad laboral que se refleja en dobles funciones, esto se puede verificar en los perfiles desempeñados por los propios entrevistados (cronista y conductor, director de noticias y conductor, conductor de radio y televisión, productor ejecutivo y conductor, editor y productor, entre otros).La polivalencia laboral repercute en los equipos de trabajo, en su rendimiento y en la calidad informativa, sumado a que las mediciones asincrónicas de rating.

(...) Antes del noticiero hacemos como una reunión entre nosotros para ver qué hacer. Tenemos ganas de tener algún jefe como para hacer una reunión y definir cuáles son los títulos. Y estamos encontrando dificultades, para ser honestos (...). (E22 Productora noticiero, Mendoza)

\footnotetext{
${ }^{6}$ Los equipos de los noticieros emitidos en horario central en AMBA están integrados por un número que ronda las 20/25 personas, en tanto que en el resto de los canales estudiados ese número se reduce a la mitad.
} 
Aunque contradictoriamente a lo que menciona esta productora, un Editor de Rosario (E19) asegura que desde los jefes de equipo tampoco hay un espacio para discutir los temas del día, las demandas son de tipo local, se revisan las agendas oficiales (gobernación, municipalidad, secretaría de cultura) y se fijan los temas para cumplir con el servicio de noticias.

Como afirman Martinchuk y Mietta (2007) una de las clave del trabajo es el equipo para lograr un producto de calidad en la pantalla. Las divisiones de trabajo generan tensiones, los autores entienden que es vital solicitar ayuda de los colegas sin invadir los lugares de trabajo, el noticiero necesita tanto del trabajo creativo de periodistas y productores como del trabajo técnico. Sin embargo, existen mecanismos de control y jerarquías delimitadas para la toma de decisiones. Las categorías teóricas de código de trabajo y de código laboral propias de la sociología del trabajo son útiles para comprender las relaciones que se establecen dentro del proceso productivo. Mientras que el código de trabajo considera la división del trabajo, las economías de tiempo y las aptitudes del trabajador para llevar adelante sus actividades (saber hacer), el código laboral refiere a los mecanismos de coordinación/cooperación y/o control empleados por las empresas y las resistencias ejercidas por los trabajadores (saber ser). Se vincula al control externo que se ejerce por fuera del proceso productivo a través de distintos niveles de supervisión acordes al grado de especialización de la empresa (Da Silva y Monteiro, 2000; Roldán, 2010, 2011). En el caso de los noticieros identificamos la existencia de división de trabajo y economías de tiempo que deben cumplirse para lograr la emisión diaria del producto informativo. Asimismo, la presencia de diversos perfiles laborales, ya sea bajo una lógica de especialización funcional o de polivalencia laboral, conlleva cierta jerarquización del proceso productivo, así el productor general o el director del noticiero son los responsables máximos del producto a emitir, a la vez que son los «guardianes» de la línea editorial del medio. Estos actores tienen la capacidad de ejercer control simple o directo sobre el resto de los responsables de equipo, en tanto que existen formas de control grupal que garantizan que cada uno cumpla con la actividad asignada. Finalmente, operan formas de autocontrol, en este sentido los trabajadores identifican cuáles son los límites dentro del ambiente laboral, y también ofrecen cierta resistencia, tal como comenta una conductora:

El tipo que evadió el control y lo balearon. ¿Qué hacen? van a Clarín y ven cómo tituló. No hay un cuestionamiento [...] El titulo fue: «Evadió un control: lo balearon» y abajo: «el motociclista recibió un tiro por la espalda y terminó internado".ii Recibió!! Nunca ponen gendarmes (...) Yo al aire, obviamente, hago alguna "vueltereta» y eso me ha valido por el auricular: iiiilee textual!!!!!! [...] No sé cuánto hay de comodidad para evitarte un quilombo. (E1 Conductora, AMBA)

La posibilidad de quebrar con el orden establecido o con el guión pautado deriva en llamados de atención u otras instancias por la «falta» cometida. Por otro lado, 
trabajadores suelen manifestar cierta atracción o "enamoramiento» hacia sus puestos de trabajo por la visibilidad propia de los medios de comunicación (Vicki Mayer et al., 2009), así lo relata un entrevistado:

y como productor ejecutivo estoy desde octubre del año pasado (...) Yo de chico miraba Telenoche como algo: «Guau, cómo se hace», y la primera vez que tuve la oportunidad de ponerlo al aire (...) cuando volví a mi casa no podía creerlo. (E17, Productor Ejecutivo AMBA)

Otro punto esencial a considerar en la producción de un noticiero está ligado a los minutos que tendrá al aire, en general se extienden por una hora y media o dos en la que hay que exponer un abanico de temas: políticos, económicos, sociales, policiales y secciones más relajadas.

Un rasgo en común de los noticieros está dado por las diferencias de producir para la primera mañana y el horario central. El informativo matutino se constituye a medida que se emite, es más inmediato, menos estructurado, es común el «último momento" y las salidas telefónicas. En los noticieros del horario central la información está de algún modo pre seleccionada, habitualmente las agendas periodísticas se confeccionan a la mañana, los actos, marchas, accidentes, asesinatos u otros temas noticiables. A diferencia del resto de los informativos, los noticieros del horario central intentan sumarle interpretación, esto se debe a la competencia que rige con otros medios de comunicación, incluidas las redes sociales, por este motivo deben generar estrategias de complementariedad.

Una de las coincidencias entre los noticieros de AMBA, Córdoba, Mendoza y Rosario consiste en la posibilidad que tienen los periodistas y cronistas de proponer temas y las posibles coberturas, aunque es el productor ejecutivo (o en su defecto el productor general del noticiero) quien finalmente determina qué cubrir y eso es lo que se refleja en la pantalla. Otro punto en común es el uso de tecnologías físicas, las mismas colaboraron con la desverticalización productiva, por ejemplo los grupos de Whatsapp (o servicios similares) creados para ser usados con los teléfonos móviles juegan un papel destacado al momento de proponer temas y decidir de modo permanente sobre las coberturas. Se transforman las dinámicas de trabajo, se diluye la mediación cara a cara, según una Cronista de AMBA:

Estaba bueno el intercambio, el estar en la reunión porque uno aporta desde su saber en la calle, pero te digo la verdad, hay cuestiones que son inevitables (...) Es cierto que no es lo mismo, eso es una de las cuestiones que se habían planteado, pero bueno la distancia te demanda otra forma de trabajo. Y de última cuando vos estas en la nota, valoras en función de lo que te parece. (E10, Cronista AMBA) 
La exclusión de profesionales de las reuniones de producción, expone la jerarquización y la delimitación de tareas en los informativos. En AMBA, además, parecen regirse por una mayor fragmentación del proceso productivo, con perfiles laborales determinados y en los cuales probablemente exista mayor especialización funcional. Un ejemplo lo brinda un cronista:

(...) me llama uno de los tantos productores que tiene el noticiero para decirme te toca tal tema. $\mathrm{Y}$ yo me encargo de averiguar, y con ese productor hacemos placas, mapas, dibujos, armamos la salida. Yo armo lo mío, conseguir la información. (E30 Cronista, AMBA)

Ahora bien, aunque tengan capacidad propositiva, eso no implica que sus opiniones sean incorporadas, esto puede pasar porque afecta algún interés del grupo o contradice la línea editorial. Algo similar ocurre en el resto de las ciudades, aunque se destaca presencia de perfiles laborales polifuncionales.

En términos teóricos, la consideración de los valores/noticia dentro del proceso productivo de los noticieros es esencial porque contribuye a las prácticas rutinarias del equipo técnico y periodístico. Estos valores/noticia se activan para la selección del material disponible en la redacción y son guías para la presentación del contenido final. Se constituyen así en un conjunto de conocimientos implícitos que delimitan el trabajo en la redacción. Asimismo pueden descomponerse en cinco criterios que retomaremos para el análisis: sustantivos (importancia e interés de la noticia), producto (incluye los recursos técnicos y materiales disponibles, el formato y la extensión de la noticia, su actualización y la calidad), medio (supone una revisión tríadica del suceso, la relevancia temática y las imágenes disponibles), público (es la imagen que los trabajadores de los medios sobre todo los que realizan el trabajo creativo tienen de sus audiencias) y competencia (con otros medios y para obtener exclusivas).

Finalmente, las economías de tiempo implementadas en la producción de una noticia condicionan los procesos de organización productiva y del trabajo en los canales de televisión, en sus diferentes fases (pre producción, producción per se y post producción), principalmente en lo que respecta a los criterios de selección y cobertura de temas como la edición y presentación de las noticias.

En el próximo apartado intentaremos elucidar de qué modo se da la elección de temas, el tipo de cobertura y las razones económicas que interfieren en la producción de contenido. 


\section{Selección de temas, edición y puesta al aire}

La elección de los temas que compondrán un noticiero depende de una conjunción de elementos y de estrategias para la diagramación del programa informativo. Entre ellos se tiene en cuenta la continuidad temática, el rating, la agenda del gobierno (nacional, provincial o local) y la incidencia del tema en otros medios (periódicos, radios, señales de noticias 24 horas) o en las redes sociales (Facebook, Twitter).

En relación a la puesta al aire de este tipo de noticias, las emisoras televisivas utilizan narrativas propias de los géneros televisivos. Las audiencias consumen, habitualmente, series ficcionales donde se recrean situaciones delictivas o reality shows de policías, no se trata solo de informar sino de entretener a las audiencias. En las últimas décadas se dio un pasaje de un noticiero puramente informativo a uno del tipo «infoentretenimiento» (Radunski, 1999).

Montero y Ferré-Pavia (2017) indican que cuando Guy Debord escribió en la década del noventa sobre la sociedad del espectáculo, las barreras entre información (la llamada noticia dura) y entretenimiento (noticia blanda) eran claras. Sin embargo, la confluencia entre información y entretenimiento aparece y se instala con fuerza en el siglo XXI como alternativa para competir con las fórmulas del entretenimiento mediático, las audiencias están más atraídas por estos contenidos en comparación con los que requieren otros niveles de atención. Estos autores entienden que la espectacularización de las noticias puede centrarse en: la personalización (focalizar la información en individuos concretos), el protagonismo (de los cronistas y periodistas al presentar las noticias) y la dramatización (resaltar los aspectos conflictivos, la historia individual, apelar a los aspectos emotivos y la empatía).

La dramatización se enfocó en la idea de peligro permanente e inminente. En la fragmentación de los relatos mediante la narración de episodios descontextualizados, la centralidad en las víctimas y en la figura del victimario, sindicado como delincuente joven, varón y pobre, y la instauración de modalidades delictivas.

En relación a la selección de temas los entrevistados manifiestan que existen determinadas pautas. Sin embargo, los trabajadores -independientemente del rol que ocupen - tienen tan internalizadas sus prácticas y rutinas que deben esforzarse para identificar cuáles son esos elementos, qué se prioriza, competencia/complementariedad con otros medios, temas instalados durante el día, posicionamiento de títulos sin tener la información y la incidencia de la emisión en vivo que ya fue mencionada en el apartado anterior.

Antes hemos definido noticiabilidad como la serie de requerimientos que deben contener los acontecimientos para obtener estado público. Así, los pro- 
cesos de rutinización y estandarización de las prácticas productivas quedan sujetos tanto a la noticiabilidad como a la imprevisibilidad de los acontecimientos (Wolf, 1987).

No obstante, en los trabajadores de los medios opera un proceso de naturalización y automatización de las propias prácticas, al ser consultados acerca de la selección de noticias y los criterios exigidos a los acontecimientos, las respuestas se repiten casi sistemáticamente.

uno lo hace ya tan automático que tendría que ponerme a pensar un poquito cuáles son las características, el criterio, las características de la noticia. Eso que te dije recién, el impacto que tiene la noticia en la sociedad, la sensibilidad. (E39 Productora, Córdoba)

Los entrevistados admiten que hay un criterio de selección, cierto olfato periodístico que se adquiere con la experiencia e incluye identificar la gravedad de un acontecimiento, los elementos de espectacularidad y los daños. Si no son significativos, la cobertura se pone en duda. Se considera, además, el número de víctimas en un siniestro o si está involucrada alguna persona pública. Estas manifestaciones coinciden con el criterio sustantivo señalado por Wolf (1987) debido a que se pone en juego el interés de la noticia, el impacto nacional o local, la cantidad de personas afectadas y las posibilidades de evolución de ese tema.

El impacto que nosotros valoremos que pueda tener en la sociedad. Una violencia de género es fuerte. Con la ola de asaltos el grado de violencia que pueda haber tenido, o se trate de una víctima conocida (...) Si hay muertos, si hay heridos, si hay violencia en el robo. (E13, Director de noticias y conductor, Córdoba)

Las palabras a las que recurren los trabajadores consultados se vinculan con evaluar la trascendencia del hecho, la elección de los temas del día recae en la supuesta obviedad de los acontecimientos. Por este motivo, las frases más utilizadas por los entrevistados para indicar qué hechos se convertirán en noticia son: «caen de maduro", el "tema lo requiere», "de tu agenda vos sabes cuál es la más importante» o «(...) cuando hay algo que está instalándose, hay cosas que son obvias, de manual, no sé especificarte en qué». De modo complementario, los actores involucrados en la producción de noticias entienden que se valora el peso informativo y las imágenes para mostrar, a través de videos y la cobertura de la emisora in situ con los periodistas del canal en búsqueda de los testimonios. Esto implica cumplir con alguna de las máximas televisivas y con las instancias de reconocimiento que le permiten al público identificar que se trata de un producto diferente todos los días, pero con lógicas y formatos idénticos cada jornada (Zallo, 1988; Richeri, 1994; Bustamante, 1999; Williams, 2011). 
la cobertura de cualquier tema, se privilegia la imagen. Es decir, que podamos ofrecer en la pantalla una imagen que pueda narrar por sí misma un hecho determinado y que resulte atrayente al televidente. (E4 Cronista, Rosario)

Lo expuesto se liga a los criterios producto y medio (Wolf, 1987) ya que deben contemplarse al momento de diagramar las noticias: el formato, la duración, el tipo de imágenes disponibles y las diversas fuentes.

Por otra parte, es importante destacar que en los casos estudiados sobre violencia, delito e inseguridad, los temas distan de recibir coberturas similares, es decir no es lo mismo la presentación de un caso policial que uno sobre corrupción.

Del mismo modo, una cronista de AMBA (E10) aporta un enfoque complementario, las decisiones se toman en función de lo que se considera noticia, de aquello que puede interesar o generar expectativa en el público u otro tipo de sentimiento, aunque estima que en algunos casos el nivel de descripción es innecesario y no compatible con los gustos de las audiencias. En este punto aparece el criterio de valor/noticia ligado al público, es decir que los trabajadores del noticiero interpretan las necesidades de su público, la existencia tecnologías como el rating permiten medir parcialmente esas expectativas, además algunas emisoras crearon áreas especializadas en el procesamiento de datos.

Al mismo tiempo, varios trabajadores, principalmente, de los canales de Mendoza, Córdoba y Rosario remarcan la incidencia de la agenda de gobierno para definir los a temas a cubrir, en este sentido se tienen en cuentan dos elementos: el carácter local y oficial de esa información, la pauta oficial y las necesidades económicas de estos medios influyen en la definición de sus agendas.

la agenda de gobierno tiene bastante prioridad, la actividad oficial, los policiales tienen mucha importancia. El Ministerio de Seguridad manda partes diarios y es fundamental [¿hay una decisión editorial de priorizas esos temas?] no es que nos bajan línea directa pero sí. (E22 Productora noticiero, Mendoza)

En un sentido similar, un camarógrafo de Mendoza explica que muchas imágenes se extraen de YouTube, y que el gobierno genera muchas noticias ya que cuenta con su propio sistema de prensa, así elaboran y difunden para todos los medios, esto es lo que Arrueta (2010) denomina noticias enfrascadas, que pueden aparecer como propias de esa emisora.

Asimismo, se menciona la participación del ciudadano, público o consumidor que diariamente se comunica para hacer denuncias. En las respuestas recibidas 
y desde la percepción de los profesionales de los medios, se enfatiza que los sectores sociales más vulnerables entienden que la visualización del tema en la televisión es un modo de hacer justicia, «(...)en líneas generales lo que podes hacer es reflejar un caso que es representativo de muchos otros (...); obviamente no se cubren todos y a veces el criterio tiene que ver con cuestiones de agenda» (E2 Productora periodística, AMBA).

En función de lo expuesto, se podría pensar si la calidad informativa se resiente con la utilización de tecnologías, según McQuail (2000) el elemento esencial en relación a la calidad informativa es la objetividad. La característica relevante sería la postura neutral hacía el objeto de información (ausencia de subjetividad o implicación personal), ausencia de partidismo, respeto de la exactitud y de los criterios de veracidad.

Este principio se pone aún más en juego en la era de las redes sociales, los empresarios y profesionales de los medios exploran alternativas de comunicación que los acerquen a audiencias fragmentadas y exigentes. Las tecnologías permiten aplicar la innovación a todas las fases productivas. La accesibilidad de la información está relacionada con las fuentes y a las redes informativas establecidas por cada medio (García Orosa \& López García, 2016). Ahora bien, los medios de comunicación pueden decidir qué relevancia le otorgan a los hechos que le llegan desde las propias audiencias, en estos casos los criterios de selección y tratamiento de los mismos queda sujeto a las propias características y limitaciones que delimitan la producción de noticias. La calidad informativa podría verse afectada en la calidad del formato (ligado a aspectos técnicos) o en la calidad de los contenidos (proceso de selección de la información y proceso de elaboración de la noticia) dada la procedencia de la misma y los mecanismos establecidos para el chequeo de la información.

Como explicamos en el primer apartado, las reuniones de producción son frecuentes en las señales de AMBA, pero no en el resto del país, y esto también repercute en la elección de temas. En palabras de un productor general:

La selección de temas tiene que ver con varias cosas (...) Lo que tenés es una reunión de producción, más en Buenos Aires, es el start up, en lugares como el interior, esa reunión es más dificil de hacer (...) Entonces lo que se va haciendo en el noticiero de la noche es profundizar lo que pasó durante el día. (E37 Productor General, Rosario)

Se debe enfatizar sobre las estrategias de competencia, complementariedad y diferenciación que llevan adelante las emisoras en relación a sus competidores directos, es decir otros noticieros, y en relación a los diarios, las radios, incluso la incidencia de las redes sociales. 
Independientemente del canal, los entrevistados afirman que están atentos a lo que hacen los otros informativos. De hecho, en los horarios de emisión de los noticieros se encuentra en el control central una televisión encendida en el canal de la competencia. Hay temas que son comunes, aunque los entrevistados asumen que se diferencian por el tratamiento, el foco y la continuidad informativa.

Por lo general, acá en Rosario es mucho ir viendo lo que está haciendo el otro, son muy pocas las oportunidades en las cuales uno elige en hacer determinada cobertura, sobre todo por una limitación de recursos. Entonces, hay como una necesidad de si tener lo básico. Si no tenés el choque del día, el policial del día, la acción política del día, acá (y marco que es acá) sienten que se quedan por fuera del núcleo informativo. (E19 Editor, Rosario)

Algunos cuestionan esta forma de producir, la idea de buscar en el periódico qué casos ameritan cobertura, «no coincido para nada, agarran los diarios más importantes y ahí se fijan qué noticias están buenas, no sé qué, y te mandan a hacer una noticia del diario — La Nación y Clarín— (E8 Camarógrafo, AMBA). En este fragmento, se visualiza el modo en el cual operan los mecanismos de control, el trabajador manifiesta estar en desacuerdo con las formas para seleccionar los hechos a cubrir, no obstante debe cumplir con la tarea asignada y no puede ejercer resistencia como en otros roles.

En este caso se observa la dicotomía complementariedad/competencia de los medios y aparece el criterio competencia mencionado por Wolf (1987). La competencia fomenta una especie de vigilancia activa en relación a los contenidos exhibidos por otros medios similares, a su vez rigen criterios de complementariedad al intentar reinventar o interpretar una noticia desde un ángulo diferencial, sobre todo cuando se trata de una temática que ha circulado durante toda la jornadas en diversos medios y redes sociales.

Otro criterio que se tiene en cuenta en los noticieros del horario central son los temas instalados a lo largo del día.

Son muchos los factores que hacen que una nota quede en agenda o no (...) Cuando vos llegas a las 8 de la noche tuviste todo un día de arrastre, de posicionamiento de algo (...) si hay una noticia que a las 11 de la mañana la viste en todos lados, seguramente no sea la apertura del noticiero de la noche porque ya está. (E2 Productora periodística, AMBA)

Con menor frecuencia sucede que se posiciona un título sin contar con el material para desarrollar la nota, pero la temática resulta atractiva y por eso se considera para la apertura o «venta» del noticiero. 
Inclusive a veces nos arriesgamos y ponemos algo que vamos a tener y después no lo tenemos por varios motivos, porque se cayó, porque se arrepintió (...). Incluso muchas veces ponemos en título algo que no tenemos una nota o material contundente, sino que el titulo llama la atención. (E7 Productor Noticiero, Rosario)

Se verifica, también, lo que podemos denominar encadenamiento temático, es decir el tratamiento de determinados acontecimientos por la presencia de noticias previas que tomaron estado público. De otro modo, esos casos probablemente no cumplirían con los criterios de noticiabilidad para formar parte del informativo.

[Vos pensas que en el caso de Villa Mascardi ¿se cubre porque ya tenías un conflicto previo con lo de Maldonado?] Primero, con Maldonado tenías un desaparecido y ayer (por Villa Masacardi) tenías un muerto, al lunes ya sabias que era por una bala oficial. Obviamente, que haya existido Maldonado hace que la situación se cubra rápidamente. (E2 Productora periodística, AMBA)» ${ }^{7}$

Por último, un hallazgo de la investigación se vincula con la «geolocalización» (dimensión territorial del delito) como variable para la selección de temas y la relevancia de la zona geográfica para el tratamiento noticioso. En ocasiones, hay situaciones de tensión porque los periodistas se niegan a ir a determinados lugares, mientras que los productores (muchos de ellos antiguos cronistas) consideran necesario realizar la cobertura in situ, la idea de hacer periodismo de «escritorio» o periodismo por «correo electrónico» es inadmisible para algunos trabajadores, aunque podría configurarse en una tendencia con la constante utilización de las redes sociales.

Los trabajadores admiten que hay barrios o situaciones en las cuales hacer un registro es complicado y riesgoso. La cobertura de la noticia no difiere de otros hechos, se modifica el contexto y el riesgo físico que implica ingresar en determinados barrios, entonces deben tener ciertas precauciones, «Si nos dicen: che, acá no se puede entrar porque está heavy, bueno sí, no entramos, no vamos a poner la vida en juego de nadie. (E17 Productor Ejecutivo, AMBA)». Por su parte, una jefa de producción y conductora mendocina (E32) relata:

Hay lugares que son complicados y podés pedirle a la policía que ponga un móvil ahí mientras vos estas trabajando, lugares a donde vos vas con

\footnotetext{
7 El caso Maldonado, se refiere a la investigación realizada por la desaparición de Santiago Maldonado tras un allanamiento realizado por la Gendarmería Nacional el 1 de agosto de 2017, en el Pu Lof en Resistencia de Cushamen (Chubut, Argentina). Maldonado había participado el día anterior en una manifestación por la lucha de tierras ancestrales tradicionalmente usadas por la comunidad mapuche. Para disuadir la movilización intervino Gendarmería Nacional y desde ese momento no se supo sobre Maldonado. Su cuerpo sin vida fue hallado en el Río Chubut el 17 de octubre de 2017.
} 
gente que es referente ahí, ONG o un cura, también tiene que ver mucho con la forma en que accedes a esos lugares y de la manera en que te planteas vos para entrar.

Otra arista de la geolocalización se relaciona con la confluencia de la localización del delito, la/s víctima/s, la espectacularidad del hecho y las expectativas del público de acuerdo a la imagen que los productores tienen sobre sus propias audiencias.

(...) hay una cosa en el morbo de la gente, de crímenes puertas adentro, en un country. A la gente le da morbo porque se abre como una ventana a una vida de la que no tenes conocimiento y desnuda esa vida (...). El crimen de Farré con los condimentos que tenía, policialmente hablando, mediación de divorcio, separación de bienes, abogados en el medio, un country, un hombre exitoso, una mujer linda y exitosa, que termina apuñalada en el guardarropa de la casa. (E17 Productor Ejecutivo, AMBA)

La geolocalización se vincula directamente con el eje equilibrio/balance propio del criterio producto dentro del valor/noticia, ya que considera la cobertura geográfica, las clases sociales y etarias para relacionarlas con las necesidades de la audiencia.

Una vez expuestos los principales mecanismos que definen la selección y cobertura temática en los noticieros estudiados, se expondrá la puesta al aire de los programas.

\subsection{Puesta al aire y eCOnomías de tiempo}

La puesta al aire del noticiero es compleja, a diferencia de otros productos de las industrias culturales, los informativos conservan una de las características nodales de la televisión, su transmisión en vivo y en directo, esto supone la imposibilidad de subsanar errores y tiempos de pre producción limitados por el horario de emisión. En este sentido, la definición de noticia proporcionada por Altheide (1976, en Wolf, 1987) es útil al considerarla como el producto de un procesos organizado que supone una visión sobre hechos con el objetivo de unirlos, aplicarles valoraciones, establecer relaciones entre ellos y darlos a conocer de modo que cumplan con la función de entretener a las audiencias. Estos requisitos se reúnen cuando el noticiero «sale al aire».

\footnotetext{
8 Fernando Farré asesinó de 66 puñaladas en agosto de 2015 a su ex pareja Claudia Schaefer en un barrio privado en la localidad de Pilar. El caso tomó estado público por el carácter del crimen y porque fue realizado por un empresario.
} 
En relación a la puesta al aire, los entrevistados coinciden que los móviles en vivo se incluyen con mayor frecuencia en los noticieros matutinos o del mediodía porque es cuando las noticias están en desarrollo. Los móviles se centran en los temas coyunturales y buscan generar empatía con el público. Ahora bien, es una de las pocas instancias del proceso productivo en la cual el emisor pierde parte del control sobre el producto, incluso se pueden filtrar declaraciones que no coincidan completamente con la línea editorial del medio o con las ideas fuerza y hegemónicas que se buscan instalar. En esos casos los propios cronistas o conductores tienen la tarea de «reencauzar» la nota. Hay diversos criterios para realizar una cobertura en vivo: la distancia entre la emisora y el acontecimiento, la espectacularidad del hecho y la disponibilidad de personal. En este sentido, se entremezclan razones económicas (enviar un móvil implica un gasto de dinero y una serie de responsabilidades sobre los equipos y los trabajadores) con cuestiones sociales, políticas e incluso intrínsecas al propio medio como la línea editorial.

En los móviles se verifica claramente la existencia de economías de tiempo y el «justo a tiempo», es decir emprender un proceso productivo que redunde en la puesta al aire del material justo al momento de emitir. En ocasiones, los cronistas llegan al lugar de los hechos y deben «salir al aire» rápidamente, esto impide que puedan tener un panorama claro de la situación y que se pierda calidad y claridad en esa información. La inmediatez, la producción flexible y la competencia con otros canales televisivos favorecen este tipo de situaciones:

Otro eje nodal para la puesta al aire es la edición de las notas, en los noticieros de AMBA junto a las coberturas, los cronistas devuelven un "punteo» para que los editores periodísticos identifiquen rápidamente las partes o piezas visuales más destacadas, en el resto de los noticieros estudiados esto ocurre con diferentes grados de frecuencia, incluso se apela a Whatsapp para realizar este tipo de marcaciones, la falta de tiempo, sumado a la polivalencia antes mencionada fomentan este tipo estructura productiva y cuestionan la calidad otrora exigida a los noticieros. Además, existen diferencias de acuerdo al tipo de noticias presentadas, el uso de las palabras y la posibilidad de revestirla con imágenes (propias o derivadas del público, las cámaras de seguridad o de las redes sociales).

(...) ahora la gente sube videos y si están en buena calidad se reeditan y la información se hace desde ese video que mandó la gente, porque no llegamos a cubrirlo, o porque paralelamente hay dos cosas y tenés un solo cronista. Entonces bueno, tenés que elegir qué es lo que hacés, darle prioridad al tema. (E23 Productora Ejecutiva, Mendoza)

En esta declaración se observa la tensión entre cubrir un tema de relevancia y la escasez de personal, es decir que el presupuesto fija límites a las posibilidades de efectuar determinadas coberturas, de este modo el uso de las tecnologías física adquiere un rol importante al momento de editar y poner a disposición la información. 
A su vez, se observa cierta tendencia a interpretar o comprender los intereses del público específico de ese medio:

cuando hay imágenes grabadas del robo, del asalto. De cajón la hacemos esa viste, muchas veces te lo manda la gente inclusive en el whatsapp, entonces eso te ayuda a alimentar mucho la nota, tener la imagen del robo a la gente la hace bien ver, le gusta ver eso. (E34 Productor//cronista, Rosario)

Por otra parte, la naturaleza del delito impone una lógica para la presentación de la noticia y la interpelación a la audiencia:

(...) Cuando hay un tema de corrupción siento que somos más letales. Hay hechos de corrupción muy burdos, entonces, buscamos la manera de mostrar esto pero no siendo... no sé cómo explicártelo que sea didáctico, la manera de titular. (E17 Productor Ejecutivo, AMBA)

En la producción de un noticiero, al igual que en otros productos culturales en especial los ligados a la emisión o edición continua se advierte la existencia de cero stock $^{9}$ de tiempo. En este caso, las distintas fases productivas se llevan adelante casi de modo simultáneo por los cual los tiempos de edición de una nota pueden coincidir con el momento de transmisión, por este motivo «el aire» le «pisa los talones» al proceso productivo general y es necesario el trabajo en equipo para garantizar la emisión diaria.

La producción del noticiero debe considerar el tiempo que estará en el aire, el cual regularmente varía entre una hora y media y dos horas. Como hemos adelantado en la pre producción se diseña un guión que tanto el equipo técnico como periodístico utilizará para la puesta al aire. Sin embargo, este diagrama puede alterarse principalmente por cuestiones de tiempo, por la incorporación de noticias de último momento o por la imposibilidad de lograr las imágenes o los testimonios buscados en el horario de emisión.

El tiempo suele ser enemigo, siempre estamos ajustados con los tiempos. La típica queja es: no tengo tiempo (...) sí, a veces nos llegan cosas que pueden estar buenas pero nos llevan un tiempo de producción. (E7 Productor Noticiero, Rosario)

\footnotetext{
9 No se debe pensar en el cero stock como el impuesto en el modelo ohnista de la fabricación automotriz, en este, se deben reducir al máximo los errores y por ello no existen componentes o insumos de reserva, se entregan las cantidades necesarias para producir. En el caso de la producción de telenovelas lo que no hay es stock de tiempo, en general, se trabaja al límite con la salida al aire y cualquier inconveniente ocasionado en algunas de las fases podría imposibilitar la entrega a tiempo del capítulo, listo para emitir a la emisora o canal que debe enviarlo al aire.
} 
Las noticias de último momento provocan una ruptura con el diagrama establecido e implica que la totalidad del equipo quede afectado a la producción de esa información. En estos casos rige la inmediatez porque en la vorágine diaria las noticias pierden valor rápidamente.

cuando surge una noticia de último momento, ahí es cuando se descontrola todo porque todo lo que tenías planeado ya no va más o puede ir pero surgió otra cosa, a veces se modifica la noticia y otras veces surge una nueva. En los dos casos es empezar a correr, a buscar información como puedas y te dé el tiempo (E12 Productora, AMBA)

Además, el modo de presentación de la noticia tiende a definir el tiempo de emisión o los minutos que estará al aire, su argumento, las imágenes que revisten la nota, la posibilidad de contar con un móvil en vivo o algún entrevistado en particular colaboran con los aspectos narrativos y el entramado de ese acontecimiento, generando un clima que permite extender (o no) una información, quien evalúa esto es el productor ejecutivo del noticiero a medida que transcurre la emisión.

Los trabajadores reconocen que «corren contra reloj» y esto les provoca estrés, admiten también que la falta de tiempo no repercute directamente en la calidad de la información.

yo creo que la calidad de la información está pobre, pero me parece que en todos los ámbitos está pobre porque no se trabaja la noticia (...) no le hacemos el seguimiento a la noticia porque la misma rutina te hace que vos no le hagas el seguimiento a esa noticia. (E23 Productora Ejecutiva, Mendoza)

Las rutinas de trabajo podrían afectar la calidad informativa, aunque se comprueba también una dinámica que desarticula y atomiza el proceso productivo. Cada trabajador se ocupa de un parte específica de ese proceso productivo, mas no controla la totalidad del mismo. Esto sumado a las disparidades de recursos técnicos y de personal establece diferencias entre los noticieros estudiados, e impacta en el producto final.

\section{Conclusiones}

En el estudio se buscó comprender la estructura productiva de los noticieros emitidos en el horario central en cuatro ciudades argentinas. Además de describir de modo general las rutinas de trabajo de los noticieros, se focalizó en la selección, recolección, tratamiento y puesta al aire de estos programas. Se reconstruyeron estos procesos de trabajo a partir de la realización de entrevistas en profundidad y las observaciones in situ. Como se ha mencionado, el trabajo se integra en una investigación que analiza la producción de noticias de delito, violencia e inseguridad de 
modo integral al contemplar la estructura de propiedad, las rutinas de trabajo, el análisis de contenido y la recepción de los mismos, por este motivo los ejemplos brindados por los trabajadores giran en torno a esta temática.

Los noticieros televisivos están insertos en las lógicas propias de la industria televisiva, la necesidad de una programación diaria y el flujo continuo imponen delimitaciones a las rutinas de trabajo. Por este motivo, las economías de tiempo y de las divisiones de trabajo actúan como factores clave para la ejecución «justo a tiempo» de las diferentes piezas informativas que componen el noticiero. Una de las diferencias entre AMBA y las ciudades de Córdoba, Mendoza y Rosario es que en la primera rige cierto grado de especialización funcional, los perfiles laborales y las jerarquías aparecen delimitados claramente. En cambio, en las otras ciudades se constata cierta polifuncionalidad con trabajadores que desempeñan dos o más tareas al mismo tiempo, además es bastante común que los empleados desarrollen sus actividades en más de un medio dentro del mismo grupo mediático.

Esta jeraquización activa mecanismos de control directos sobre los trabajadores e impone límites a la creatividad como ha quedado demostrado en varios apartados de este trabajo. Si bien, en general, los periodistas y cronistas tienen la capacidad de proponer tópicos, no son los que toman la decisión final. Igualmente, la capacidad para establecer los temas del día está en manos del productor general o de los productores que aportan una revisión integral de los temas a cubrir, los recursos disponibles y el presupuesto establecido. A esto se suman las estrategias de complementariedad y competencia que todas las emisoras estudiadas aplican para hacer más eficaz el contacto con su audiencia.

Una de los hallazgos de esta investigación se centró en identificar las diferencias existentes entre las emisoras de AMBA y la del resto de las ciudades estudiadas. Mientras que el equipo de trabajo de un noticiero de horario central de AMBA está conformado por alrededor de 20 personas, en el resto de las ciudades ese número ronda en 10. La mayor cantidad de recursos técnicos, económicos y de personal permiten otras coberturas, si bien no era uno de los tópicos de este escrito, la centralización y concentración de la producción de contenidos en el AMBA se verifica también en la producción de los informativos, principalmente esta incidencia se refleja en las noticias de carácter nacional, las cuales son provistas por los canales de cabecera de Buenos Aires.

Por otro lado, se han encontrado transformaciones en el proceso productivo por la incorporación de tecnologías físicas y de las redes sociales. El uso de la telefonía móvil impone otros ritmos para la selección y cobertura de temas, incluso para la edición o compaginación final de las piezas informativas dado que los cronistas suelen hacer marcaciones a los editores a través de sus teléfonos personales. Una de las preocupaciones manifiestas es la posibilidad de recaer en un periodismo de «escritorio», de "correo electrónico» o de «teléfonos móviles». Esto traería aparejado cierta perdida en la calidad informativa como han alertado varios entrevistados. 
A modo de cierre, queda preguntarnos acerca del lugar de los noticieros televisivos en las sociedades actuales. En especial los informativos emitidos el horario central nocturno deben diseñar estrategias que le permitan presentar un contenido renovado, sabiendo al mismo tiempo que las audiencias han consumido esa información a lo largo del día, tal vez de modo fragmentado y por diferentes medios o redes sociales. Es posible que estos programas sean visualizados por el público como "curadores de noticias», los cuales proporcionan de modo organizado, por un espacio de tiempo delimitado y con un tipo de estructura particular los principales temas del día.

\section{Referencias bibliográficas}

Arrueta, C. (2010). ¿Qué realidad construyen los diarios? Una mirada desde el periodismo en contextos de periferia. Buenos Aires: La Crujía.

Aspillaga, P.,Miguel de Bustos, J.C. \& Zallo, R. (1998). Las industrias culturales en la economía informacional. Evolución de sus formas de trabajo y valorización, Revista Zer, Vol 3, N. ${ }^{\circ}$ 5, País Vasco: Universidad del País Vasco.

Alsina, M. (1993). La construcción de la noticia, Barcelona: Paidos.

Bustamante, E. (1999). La televisión económica, Barcelona: Gedisa.

Carboni, O. (2015). Los procesos de organización productiva y del trabajo en las tiras diarias de la televisión abierta argentina (2002-2012). Tesis de Doctorado en Ciencias Sociales, Buenos Aires: UBA.

Clauso, R. (2010). Cómo se construyen las noticias. Buenos Aires: La Crujía.

Da Silva, R. \& Monteiro, L. (2000). Tecnología y cambio tecnológico en la Sociología Latinoamericana del Trabajo. En De la Garza, E. (comp.) Tratado Latinoamericano de Sociología del Trabajo. México DF: Fondo de Cultura Económica.

García Orosa, B. \& López García, X. (2016). Las redes sociales como herramienta de distribución on line de la oferta informativa en los medios de España y Portugal, Revista Zer, Vol. 21-Núm. 40.

Golding, P. \& Elliot, P. (1979). Making the news,. Londres: Logman.

Henry, L. (2013). Flexibilización productiva y difusión del trabajo independiente en la prensa escrita argentina. Un estudio sobre las condiciones de empleo de los periodistas colaboradores. Núcleo Básico de Revistas Científicas Argentinas (Caicyt-Conicet). N. ${ }^{\circ}$ 21, Invierno 2013, Santiago del Estero, Argentina, pp. 261-278.

Hesmondhalgh, D. y Baker S. (2010). Creative Labour. Media work in three cultural industries. USA: Routledge.

Jornet, C. (2006). Gestión periodística. Herramientas para lograr un periodismo efectivo y de calidad. Prometeo: Buenos Aires, Prometeo.

Katz, J. (2006). Tecnologías de la información y la comunicación en las Industrias Culturales. Una perspectiva Latinoamericana. Santiago de Chile: CEPAL.

Kessler, G. (2009). El sentimiento de inseguridad. Sociología del temor al delito. Buenos Aires: Siglo XXI. 
Kessler, G. \& Focás, B. (2014). ¿Responsables del temor? Medios y sentimiento de inseguridad en América Latina. Nueva Sociedad, 249, pp. 137-148.

Luzón, V. (2001). La irrupción de Internet en las rutinas productivas de los informativos diarios televisivos. El caso de TV3, televisión de Cataluña. Tesis doctoral, Barcelona: Universidad Autónoma de Barcelona.

Martinchuk, E. y Mietta, D. (2007). Televisión para periodistas. Un enfoque práctico. Buenos Aires: La Crujía.

Mayer, V.; Banks, M. \& Thornton, J. (2009). Nueva York: Production Studies. Routledge.

McQuail, D. (2000). Introducción a la teoría de la comunicación de masas. Barcelona: Paidos.

Montero, E. \& Ferré-Pavia, C. (2017). Elementos de espectacularización en los informativos televisivos de «prime time»: el caso de «Charlie Hebdo», Observatorio (OBS*) Journal (2017), 035-060.

Mosco, V. (2009). La economía política de la comunicación. Barcelona: Ed. Bosch.

Mosco, V. \& McKercher, C. (2009). The laboring of communication: will knowledge workers of the world unite? United Kingdom: Lexington Books.

Mosco, V. (2011). La economía política de la comunicación: una tradición viva. En Albornoz, L. (comp.), Poder, Medios, Cultura. Una mirada crítica desde la economía política de la comunicación. Buenos Aires: Paidós.

Novick, M. (2000). La transformación de la organización del trabajo, en De la Garza Toledo, E. (comp.) Tratado Latinoamericano de Sociología del Trabajo. México: Fondo de Cultura Económica.

Richeri, G. (1994). La transición de la televisión. Análisis del audiovisual como empresa de comunicación. Barcelona: Bosch

Roldán, M. (2010). Trabajo Creativo y Producción de Contenidos Televisivos en el marco del Capitalismo Informacional Contemporáneo. Reflexiones sobre el caso argentino en los 2000s. En Susana Sel (Coord) Políticas de Comunicación en el Capitalismo Contemporáneo. Buenos Aires, CLACSO.

Roldán, M. (2011). Nueva codificación de trabajo creativo televisivo y capitalismo informacional contemporáneo. Algunas implicaciones para el desarrollo en base a la experiencia argentina, Perspectiva Metodológicas, n. ${ }^{\circ}$ 12, edición noviembre 2012.

Tremblay, G. (2011). Industrias Culturales, economía creativa y sociedad de la información, Albornoz, L. (comp.). Poder, Medios, Cultura. Una mirada crítica desde la economía política de la comunicación, Buenos Aires: Paidós.

Tuchman, G. (1983). La producción de noticia, Estudio sobre la construcción de la realidad. Barcelona: Editorial Gustavo Gili S.A.

Williams, R. (2011). Televisión: tecnología y forma cultural. Buenos Aires: Paidós.

Wolf, M. (1987). La investigación en la comunicación de masas. México: Paidós.

Sanguinetti, I. (2009). El modelo de negocio en la industria de los diarios argentinos, Revista de Instituciones, Ideas y Mercados, n. ${ }^{\circ}$ 50, mayo 2009, pp. 205-240.

Zallo, R. (1988). Economía de la comunicación y la cultura, Madrid: Akal.

Zallo, R. (2011). El audiovisual: un sector en la centralidad cultural y social, en Zallo, R. Estructuras de la comunicación y la cultura, Barcelona: Gedisa. 


\section{Anexo}

\section{Cuadro I. Síntesis estructura De PROPIEDAD DE las EMISORAS ESTUdiadas}

\begin{tabular}{|c|c|}
\hline Emisora Televisiva & Descripción \\
\hline $\begin{array}{c}\text { Telefé, } \\
\text { Canal 11, AMBA }\end{array}$ & $\begin{array}{l}\text { Mayor grupo televisivo de la Argentina, integrado por nueve emisoras de te- } \\
\text { levisión encabezadas por el Canal } 11 \text { de AMBA. Desde noviembre de 2016, } \\
\text { es propiedad de VIACOM (Video y Audio Communications), un conglome- } \\
\text { rado mediático estadounidense con presencia mundial que compró las licen- } \\
\text { cias a Telefónica (dueña del multimedio entre } 1998 \text { y 2016). }\end{array}$ \\
\hline $\begin{array}{c}\text { El Trece, } \\
\text { Canal 13, AMBA }\end{array}$ & $\begin{array}{l}\text { Segundo grupo televisivo de la Argentina, aunque pertenece al mayor mul- } \\
\text { timedio del país (Grupo Clarín), con su señal cabecera en el Canal } 13 \text { de la } \\
\text { Ciudad de Buenos Aires. En 1989, el ex presidente Carlos Menem privatizó } \\
\text { los canales } 11 \text { y } 13 \text { de Buenos Aires y dio la licencia del } 13 \text { al Grupo Clarín, } \\
\text { que es su titular desde entonces (además de poseer otras cinco licencias). }\end{array}$ \\
\hline Canal 10, Córdoba & $\begin{array}{l}\text { Canal } 10 \text { de Córdoba es un canal de carácter estatal y pertenece a los Servi- } \\
\text { cios de Radio y Televisión (SRT) de la Universidad Nacional de Córdoba } \\
\text { (UNC). Desde fines de } 1972 \text {, los SRT son en un } 99 \% \text { propiedad de la UNC } \\
\text { y el 1\% del Municipio Bell Ville, del interior de Córdoba. Para poder susten- } \\
\text { tar los SRT conformaron una Sociedad Anónima para vender publicidad, algo } \\
\text { que no podía hacer la UNC como único accionista. }\end{array}$ \\
\hline Canal 12 de Córdoba & $\begin{array}{l}\text { Es una de las emisoras pertenecientes al Grupo Clarín desde 1989. Su progra- } \\
\text { mación está pendiente no sólo de El Trece de Buenos Aires sino, también, de } \\
\text { los contenidos de la señal de noticias del Grupo Clarín TN (Todo Noticias). }\end{array}$ \\
\hline Canal 3, Rosario & $\begin{array}{l}\text { Está asociado al Grupo Clarín (vía Artear), que abastece parte importante de } \\
\text { su programación diaria. Desde } 2015 \text {, su capital accionario pertenece en un } \\
55 \% \text { al Grupo Televisión Litoral (de Gustavo Scaglione, ligado a la Fundación } \\
\text { Libertad). El resto se divide entre Ana Cecilia Gollán }(19,84 \%) \text {, Carlos Er- } \\
\text { nesto Daumas }(12,88 \%) \text {, Ángel Cardoso }(3,24 \%) \text { y otros socios. }\end{array}$ \\
\hline Canal 5, Rosario & $\begin{array}{l}\text { Es una de las emisoras pertenecientes al grupo Telefé, del que retransmite } \\
\text { parte importante de su programación. }\end{array}$ \\
\hline Canal 7. Mendoza & $\begin{array}{l}\text { Forma parte del Grupo América (cuyos principales accionistas son Daniel Vila } \\
\text { y José Luis Manzano). Hasta } 2018 \text { poseía un acuerdo de programación con } \\
\text { Artear por lo que retransmitía buena parte de los contenidos de El Trece de } \\
\text { Buenos Aires, junto con - en menor proporción- América TV de Buenos } \\
\text { Aires (formalmente, La Plata), propiedad de Vila-Manzano, también dueña de } \\
\text { Radio Nihuil de Mendoza. }\end{array}$ \\
\hline Canal 9, Mendoza & $\begin{array}{l}\text { Su nombre oficial es Cuyo Televisión, Sociedad Anónima - CUTESA)- } \\
\text { es conocido como «Televida». La licencia del canal está en manos del Grupo } \\
\text { Alonso. Su programación retransmite gran parte de los contenidos de Telefé, } \\
\text { a cuya red está afiliada. }\end{array}$ \\
\hline
\end{tabular}

Fuente: Elaboración propia basada en los resultados del proyecto de investigación «De la propiedad a la recepción. Estudio integral del circuito productivo de las noticias sobre delito e inseguridad en los noticieros televisivos de mayor audiencia de la Argentina». 


\section{Cuadro II}

\begin{tabular}{|c|c|c|c|}
\hline N. ${ }^{\circ}$ & Género & Categoría Profesional & Canal de pertenencia \\
\hline E1 & Femenino & Conductora & El Trece-AMBA \\
\hline E2 & Femenino & Productora periodística & Telefe-AMBA \\
\hline E3 & Masculino & Productor de Internacionales & Telefe-AMBA \\
\hline $\mathrm{E} 4$ & Femenino & Movilera //Conductora & Telefe-Rosario \\
\hline E5 & Masculino & Editor & Telefe-AMBA \\
\hline E6 & Masculino & Conductor & Canal 3-Rosario \\
\hline E7 & Masculino & Productor & Canal 3-Rosario \\
\hline E8 & Masculino & Camarógrafo & Telefe-AMBA \\
\hline E9 & Masculino & Columnista de información policial y judicial & Telefe-AMBA \\
\hline E10 & Femenino & Cronista & Telefe-AMBA \\
\hline E11 & Masculino & Operador de placas y graf & El Trece-AMBA \\
\hline E12 & Femenino & Productora & El Trece-AMBA \\
\hline E13 & Masculino & Director de noticias//Conductor & Canal 10-Córdoba \\
\hline E14 & Masculino & Editor & Canal 10-Córdoba \\
\hline E15 & Masculino & Movilero & Canal 3-Rosario \\
\hline E16 & Femenino & Productora & El Trece-AMBA \\
\hline E17 & Masculino & Productor Ejecutivo & El Trece-AMBA \\
\hline E18 & Masculino & Camarógrafo & El Trece-AMBA \\
\hline E19 & Masculino & Editor & Telefe-Rosario \\
\hline E20 & Masculino & Cronista Radio Nihuil //Conductor & Canal 7-Mendoza \\
\hline E21 & Masculino & Productor Ejecutivo & Canal 3-Rosario \\
\hline E22 & Femenino & Productora de noticiero & Canal 9-Mendoza \\
\hline E23 & Femenino & Productora & Canal 7-Mendoza \\
\hline E24 & Masculino & Editor y Productor & Canal 3-Rosario \\
\hline E25 & Masculino & Gerente General & Telefe-Rosario \\
\hline E26 & Femenino & Cronista & Canal 7-Mendoza \\
\hline E27 & Masculino & Cronista & Canal 9-Mendoza \\
\hline E28 & Masculino & Movilero//Columnista de noticieros & El Trece-AMBA \\
\hline E29 & Masculino & Productor Ejecutivo & El Trece-AMBA \\
\hline E30 & Masculino & Cronista & El Trece-AMBA \\
\hline E31 & Masculino & Jefe de Cámara & Canal 9-Mendoza \\
\hline E32 & Femenino & Jefa de Producción y conductora & Canal 9-Mendoza \\
\hline E33 & Masculino & Camarógrafo & Canal 7-Mendoza \\
\hline E34 & Masculino & Productor & Canal 3-Rosario \\
\hline E35 & Masculino & Editor & Canal 7-Mendoza \\
\hline E36 & Masculino & Editor & Canal 9-Mendoza \\
\hline E37 & Masculino & Productor general & Canal 3-Rosario \\
\hline E38 & Masculino & Jefe de Noticias & Canal 3-Rosario \\
\hline E39 & Femenino & Productora & Canal 10-Córdoba \\
\hline E40 & Femenino & Productora & Canal 10-Córdoba \\
\hline E41 & Masculino & Web Canal & Canal 10-Córdoba \\
\hline E42 & Masculino & Productor & Canal 12-Córdoba \\
\hline E43 & Masculino & Editor Canal 12 Córdoba & Canal 12-Córdoba \\
\hline E44 & Masculino & Conductor Canal 12 Córdoba & Canal 12-Córdoba \\
\hline E45 & Femenino & Productora Canal 12 Córdoba & Canal 12-Córdoba \\
\hline
\end{tabular}

